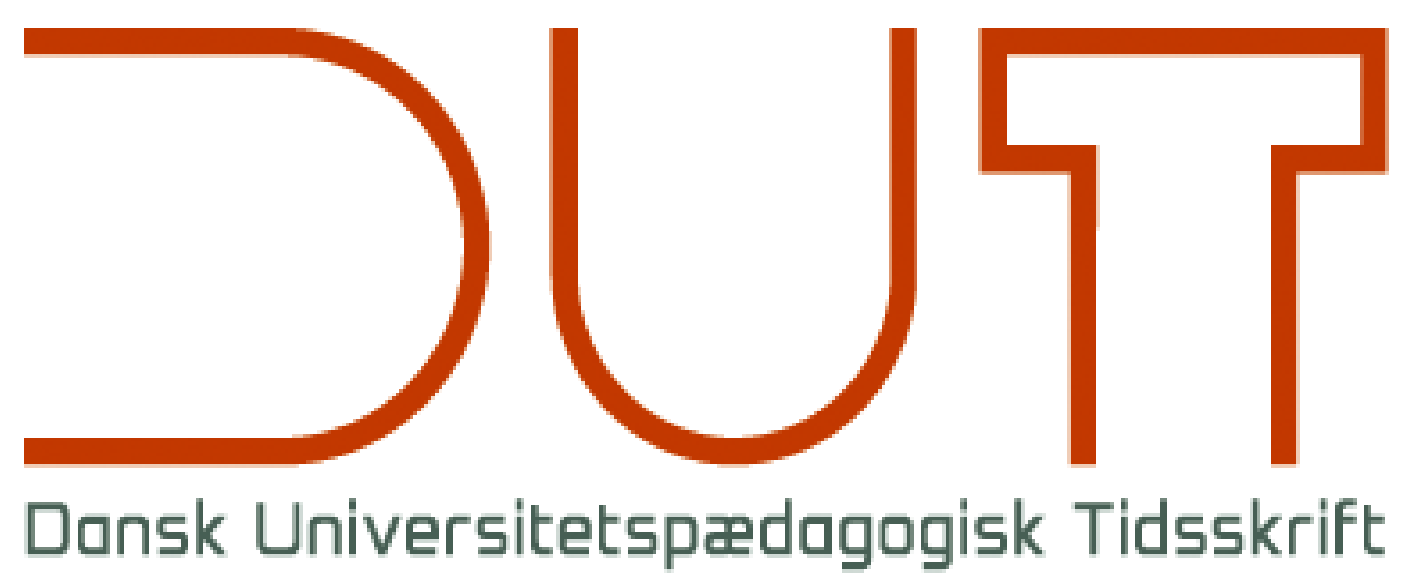

Læringsrum

Årgang 14 nr. 27 / 2019

Titel

Group versus individual supervision of university students: a qualitative case study

Forfattere

Sidetal

Janni Niclasen, Pernille Strøbæk

$118-135$

Udgivet af

Dansk Universitetspædagogisk Netværk, DUN

URL

> http://dun-net.dk/

Betingelser for brug af denne artikel

(C) Copyright
Denne artikel er omfattet af ophavsretsloven, og der må citeres fra den. Følgende betingelser skal dog være opfyldt:

- Citatet skal være i overensstemmelse med "god skik"

- Der må kun citeres „i det omfang, som betinges af formålet“

- Ophavsmanden til teksten skal krediteres, og kilden skal angives ift. ovenstående bibliografiske oplysninger.

DUT og artiklens forfatter 


\title{
Group versus individual supervision of university students: a qualitative case study
}

\author{
Janni Niclasen ${ }^{a, 1}$, Pernille Strøbæk ${ }^{b}$ \\ aFrederikshøj, school and day care and Diabetes Centre Copenhagen, Capital Region of Denmark \\ ${ }^{b}$ Department of Psychology, University of Copenhagen
}

Research article, peer-reviewed

\begin{abstract}
Background: Studies investigating strengths and limitations of group and individual supervision of university students are sparse. The aims of the present study were to investigate advantages and disadvantages of group and individual supervision, and to identify specific situations under which these two forms of supervision are particularly suitable.
\end{abstract}

Method: A qualitative study comparing a combined group/individual supervision model with a complete group supervision model among third-year Bachelor psychology students.

Results: Group and individual supervision contribute differently to the supervision process. Group supervision is preferred in the beginning of the supervision process when close ties between the group members are yet to be established and there is a process-oriented focus in the actual supervision. Individual supervision is more profitable at the end of the supervision course when content-focused supervision is needed.

Discussion: Each supervisory model contributes differently to supervision. Based on the data from present study, a combined group/ individual supervision model is recommended.

\section{Introduction}

In recent years there has been a tendency for universities to increase their yearly uptake of Bachelor students. As a consequence, university faculties are today faced with teaching and supervision of a higher number of students. Managing larger number of students has encouraged innovative approaches to both teaching and supervision, including supervision of students in groups (Akister, Williams, \& Maynard, 2009; Baker, 2014; Ginn, 2014; Scholefield \& Cox, 2016; Van Biljon, Van Dyk, \& Naidoo, 2014).

In Denmark, in 2015 an increased political focus led to a new reform for university education, the so-called 'Study Progress Reform' (or 'Fremdriftsreformen' in Danish). In Denmark most university studies are normed at five years. However, most students spend more than five years on such programs. The aim of this reform was to motivate students to complete their studies in a shorter time (Ministry of Education and Research, 2015). More specifically, the study progress reform aimed at an overall reduction in the actual length of university educations by 4.3 months by 2020 compared to 2011 (Ministry of Education and Research, 2015).

${ }^{1}$ Contact: jniclasen@gmail.com 
Traditionally, supervision in higher education in Denmark has for most parts been offered at an individual basis characterised by one student receiving supervision from one supervisor (Jensen, 2015). More recently supervision in groups, known as group or joint supervision, has been introduced. Group supervision can be defined as a group of students, typically between two and seven, receiving individual supervision from a supervisor on their own individual projects in front of the other students in the group (Jensen, 2015).

\section{Individual supervision of university students}

Research focusing on the supervision of university students is sparse (Baker, 2014; Dysthe, Samara, \& Westrheim, 2006; Nordentoft, Thomsen, \& Wichmann-Hansen, 2013; Samara, 2006). It has been suggested that participants show a preference for individual feedback and supervision (Ray \& Altekruse, 2000) and that individual supervision is considered an 'ideal supervision strategy' by most students and supervisors (Akister et al., 2009). However, it has also been suggested that this may simply be because they are used to this form of supervision (Nordentoft et al., 2013). Other researchers have pointed to some potentially negative aspects of individual supervision. These include that some students find it difficult to decide on a topic for their assignments, they have problems in assessing materials, managing their time and worrying about succeeding with their academic assignments (Akister et al., 2009). In addition, social exclusion and psychological distress have been identified as other major problems for some university students (Christie, Tett, Cree, Hounsell, \& McCune, 2008; Robotham \& Julian, 2006; Stallman, 2010).

In recent years, new models of supervision have been developed and implemented in higher education and there seems to be a trend in the direction of more group supervision and correspondingly less individual supervision (Akister et al., 2009; Baker, 2014; Scholefield \& Cox, 2016; Yamada, 2013). There may be different rationales for this. At some universities this may be introduced in order to decrease the overall number of faculty staff; i.e. as a way to supervise the increased number of students without a corresponding increase in competent supervisors (Baker, 2014; Van Biljon et al., 2014). At other institutions the aim may be didactically rooted in an ambition to increase the learning of the students.

\section{Theoretical understandings of group supervision}

Interactionist theories of human relationships and social interaction can be applied as a basic approach to understand group supervision (Blumer, 1937; Goffman, 2005). Social psychology and interactionism can help us capture the delicate and complex nature of group dynamics. From this perspective, a group is perceived as two or more people sharing a relationship with each other. Thus, the social group is, from this basic theoretical starting point, defined by its social structure rather than by the unique persons within the group. As people assigned to a group start interacting within the group, they begin to share relations and situations with one another whereby more complex group dynamics evolve.

In order to add specificity to this overall interactionist perspective about learning within groups, collaborative learning can also be drawn upon. From the broadest perspective, Dillenbourg (1999) states that collaborative learning can be defined broadly as "a situation in which two or more people learn or attempt to learn something together" (Dillenbourg, 1999, p. 1). From this perspective attention is paid to the specific structures and organization of the supervision. The students' interactions with each other and with their supervisor co-define the learning that takes place during the supervision. Collaborative learning requires the 
mutual engagement of all participants in a group supervision, and collaborative learning is seen as a coordinated effort to help each other learn. Thus, theoretically, group supervision in higher education can be understood as didactically intertwined somewhere between interactionist social psychological theory and a collaborative learning paradigm.

\section{Group supervision of university undergraduate students}

Whereas some studies have focused on advantages and disadvantages of individual supervision others have focused on group supervision. Some studies conclude that students learn core academic competencies in group supervision, including assessing theoretical and practical problems and learn to present these to their peers (Nordentoft et al., 2013). Lillejord \& Dysthe (2008) argue that students in higher education learn more productively when they are exposed to divergent voices and multiple perspectives of the research community. They state that the educational challenge of group supervision is to structure the multi-voiced learning processes that are conducive to the learning outcomes. In another study in which individual and group supervisions were compared, the authors argue that one advantage of group supervision is that students submit their dissertations at a higher completion rate. It has been suggested that this is because individual supervision is, in fact, a vulnerable process sensitive to poor student-supervisor relationships and potentially characterised by mismatches in personalities and ownership, it is sensitive to students being over-dependent on their supervisor, and sensitive to mismatches in the balance between authority and independence (Dysthe et al., 2006).

In a Finnish qualitative study focusing on Bachelor students' conceptions of group supervision, the authors found that students were overall positive about group supervision (Kangasniemi, Ahonen, Liikanen, \& Utriainen, 2011). However, certain factors must be considered, including the group size, that the schedules, principles and guidelines must be agreed within individual groups, and the nature of the supervision should be considered.

A British study, focusing on undergraduate students, compared students' experiences of individual and group supervision (Akister et al., 2009). The authors concluded that the advantages of a peer group approach include a higher completion rate and a greater student engagement. They also concluded that there were no detrimental effects of group supervision on their performances.

While most of the above-mentioned studies are of a qualitative nature one study comparing group and individual supervision made use of a combined qualitative and quantitative design (Baker, 2014). They reported an overall cut of $45 \%$ in staff time applied by using group supervision. There were no overall differences in grades between the students receiving individual and group supervision, and no differences in deferrals or extension between the cohorts were observed. In the qualitative analyses the students expressed the opinion that peer supervision was helpful in relation to 'support and sharing' and 'progress and moving forward'.

\section{Combined individual/ group supervision of university students}

While the studies above compare individual and group supervision, to our knowledge only two studies have developed and tested models in which the two supervisory forms are combined (Dysthe et al., 2006; Scholefield \& Cox, 2016). In the first English study the aim was to evaluate a mixed model tested on a large group of Bachelor dissertation students (Scholefield \& Cox, 2016). 
The model consisted of both individual supervision and supervisor-led group-based workshops. The data consisted both of online quantitative questionnaires and a qualitative focus group interview. The response rate was $51 \%$ for students and $65 \%$ for supervisors for the questionnaire study. The respondents were overall satisfied with the model, but also mentioned areas of dissatisfaction, mostly related to difficulties with accessing the supervisor.

In the second Norwegian study the authors assessed the effects of a three-pronged supervision approach of master's degree students (Dysthe et al., 2006). It consisted of group supervision containing two or three supervisors and their students, student colloquia in which the same students met without their supervisors, and individual supervision. On the basis of six internet-based student questionnaires, the researchers concluded that the three fora supplemented each other well. In the student colloquia the students received personal feedback and they served as an initial filter for new ideas and texts. In the group supervision the students received multi-voiced feedback, whereas in the individual supervision they were provided with more specific advice. Despite this study's attempts to disentangle the specific advantages of each of the three fora, it still remains to be investigated to what extent the findings are replicable in studies with other cultural and structural settings as their starting point and with other types of students. It also remains to be investigated altogether when individual and group supervision are appropriate.

\section{Objectives and research questions}

The primary aim of the present study was to investigate the advantages and limitations of individual and group supervision, respectively. The second aim was to identify under which circumstances individual and groups supervision are appropriate. This has, to our knowledge, not previously been investigated. The study was carried out among Danish undergraduate students writing their third-year Bachelor dissertations.

\section{Methods}

\section{The setting and the participants}

A total of approximately 200 psychology undergraduate students were writing their dissertations in the spring 2016. These were subdivided into classes of approximately 25 students. Most students were writing their dissertation alone, but some wrote in smaller groups of up to three students together. There was no exam related to the dissertations, but the students were given oral feedback and a grade at a short feedback meeting with their supervisor and an external examiner. The 25 students in each class were further subdivided into the supervisory groups of approximately five students each.

All classes consisted of 16 hours of teaching, and, in addition to that, each student was allocated four hours of supervision. The 16 teaching hours were related to structural and processual aspects of how to write a Bachelor dissertation, whereas the supervision was mostly focused on the academic content of the individual dissertations. Previously, the supervision had traditionally consisted of individual supervision only. During the first teaching hours the students in both classes were presented briefly with information about the study. Also, the supervisors showed up in each other's classes and presented themselves and the aims and rationales of the study. At these meetings the students were also asked to consider whether they would take part in an interview at the end of the semester. A few weeks prior to the end of the teaching they were asked to give their final consent to participate in the qualitative interviews. 
The starting point of the present study was two classes taught individually by each of the two authors (PSS and JN). The students in PSS's class received 50\% group supervision and 50\% individual supervision, whereas the students in JN's class received 100\% group supervision (See Figure 1). The students in the other classes received the traditional individual supervision. None of the students had prior experience with group supervision at the university level.
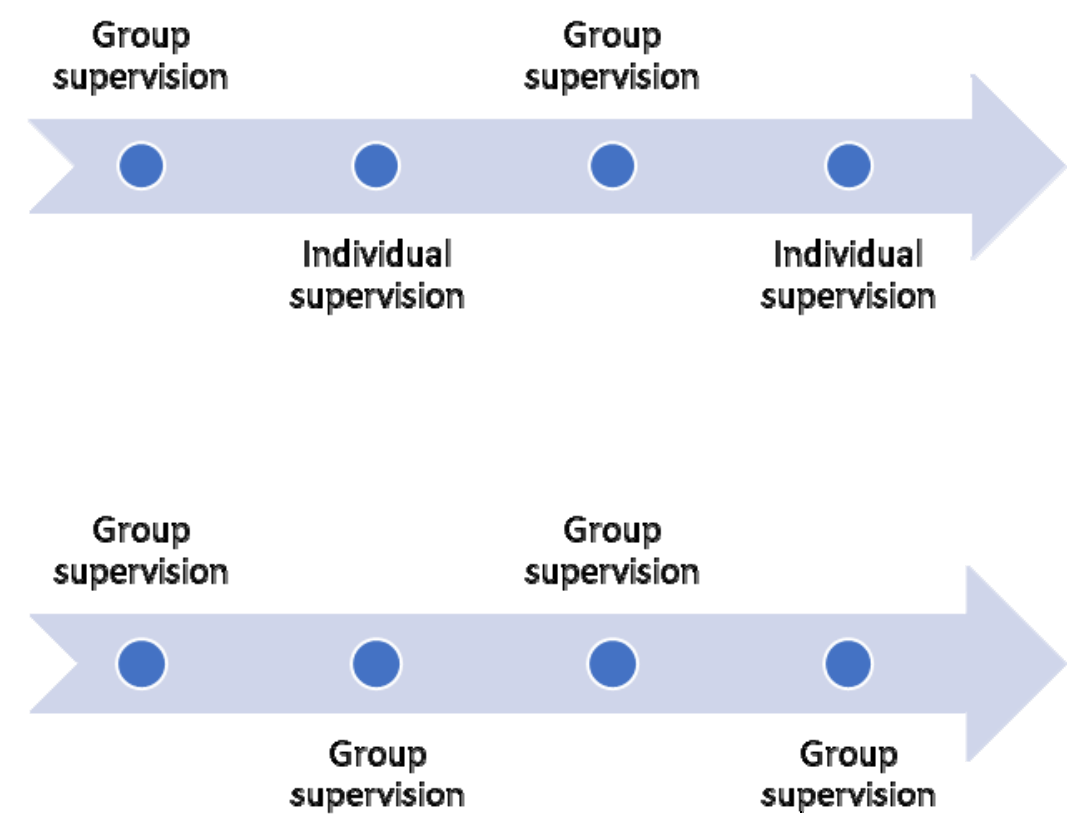

Figure 1. Flow chart showing the courses of the two supervisory models

PSS's course of supervision consisted of two occasions of individual supervision (offered in March and May) and two occasions of groups supervision (offered in February and April). The students in JN's class received four occasions of group supervision (offered in February, March, April and May). Individual supervision lasted up to one hour per session. During group supervision in both PSS' and JN's classes approximately one hour was allocated to each dissertation. Most students wrote their bachelor dissertations individually, but approximately $20 \%$ wrote them in smaller groups consisting of two or three students. Since each supervision group consisted of up to four dissertations, each supervision session lasted up to four hours.

In order to compare the two supervisory models, all decisions regarding the structuring of the class teaching and supervision were made before the beginning of the semester. The following decisions were made: prior to supervision each (group of) student(s) should send a draft of a part of their dissertation to the supervisor and to the other students in the group. Within each group the supervisor as well as the other students should prepare feedback to their drafted dissertation. The students were asked to make their comments as concrete and restrained as possible and to refer to positive elements in the text. During supervision, the feedback was given to the students' drafts, one at a time. Initially, the students gave feedback 
to each other, after which the supervisor presented her feedback to the students. During the feedback the author of the text was asked not to respond to the comments they received. At the end of the one-hour time-slot allocated to each dissertation, the authoring student could comment on the feedback, before a general discussion of the draft and a discussion about how the student should proceed. In addition to the supervision, the supervisors encouraged the students in each group to meet together without their supervisor on a regular basis in a kind of student colloquium. In order to have the best starting point for comparing the two groups in the analyses it was considered important that both supervisors were faithful to this model throughout the whole course of supervision.

\section{Procedures}

This qualitative study consists of two types of qualitative data that were collected for the present study; individual qualitative interviews and task-based focus-group interviews. The individual interviews were approximately one hour in duration, whereas the task-based focusgroups were scheduled to last for a maximum of two hours. The individual interviews were included to investigate students' individual viewpoints and perspectives. Four individual interviews were conducted, two from each of the Bachelor classes. Each of the two focusgroups consisted of three interview persons (Table 1). The task-based focus-groups were included as part of the study design to activate more voices and to shed light on potential agreements and disagreements that may emerge through the dialogues between the students when they collectively were to discuss and solve the tasks within the groups (Litosseliti, 2003; Morgan, 1996). In order to secure the students' anonymity and receive honest answers from them, we interviewed the students from each other's classes. As the interviews and analyses were carried out in Danish the quotes applied in this article were translated by a bilingual native English speaking scholar.

\begin{tabular}{|l|l|l|}
\hline \multirow{2}{*}{} & $\begin{array}{l}\text { Individual interviewees } \\
\text { (maximum one hour) }\end{array}$ & $\begin{array}{l}\text { Focus-group members } \\
\text { (maximum two hours) }\end{array}$ \\
\hline \multirow{2}{*}{$\begin{array}{l}\text { Interviewer 1 } \\
\text { (mN) }\end{array}$} & Alma (student from PSS' class) & \\
\cline { 2 - 3 } & Anders (student from PSS' class) & \\
\cline { 2 - 3 } & & $\begin{array}{l}\text { Caroline, Camilla, Catrine } \\
\text { (students from PSS' class) }\end{array}$ \\
\hline \multirow{2}{*}{$\begin{array}{l}\text { Interviewer 2 } \\
\text { (PSS) }\end{array}$} & Berit (student from JN's class) & \\
\cline { 2 - 3 } & Bolette (student from JN's class) & $\begin{array}{l}\text { Dorthe, Diana, Ditte } \\
\text { (students from JN's class) }\end{array}$ \\
\cline { 2 - 3 } & & \\
& &
\end{tabular}

Table 1. Overview of the interviewers and interviewees (the names are fictitious) 


\section{Individual interviews}

An interview guide was prepared that directed the interviews into five main themes (Table 2). However, we also allowed ourselves to follow the narratives of the interviewees and to ask questions related to these. Thus, the individual Interviews took form of being semi-structured (Kvale \& Brinkmann, 2009).

\begin{tabular}{|c|c|}
\hline Interview theme & Question focus \\
\hline 1. Background & $\begin{array}{l}\text { Student attendance: } \\
\text { - in the class teaching } \\
\text { - in the supervision } \\
\text { - in the student colloquia }\end{array}$ \\
\hline 2. Supervision & $\begin{array}{l}\text { - Student's attitudes towards supervision } \\
\text { - Student's evaluations of the supervision } \\
\text { - Student's experiences with supervision } \\
\text { - Student's ideas about supervision }\end{array}$ \\
\hline 3. Structure & $\begin{array}{l}\text { Student's attitudes towards: } \\
\text { - the way the supervision was planned } \\
\text { - the way the supervision was conducted }\end{array}$ \\
\hline 4. Feedback & $\begin{array}{l}\text { Student's attitudes towards: } \\
\text { - the provided feedback model } \\
\text { - the peer feedback } \\
\text { - the supervisor feedback }\end{array}$ \\
\hline 5. Experiences, knowledge and learning & $\begin{array}{l}\text { Student's experience with, and evaluation of, } \\
\text { supervision in relation to: } \\
\text { - learning } \\
\text { - knowledge } \\
\text { Student's recommendations and new ideas for: } \\
\text { - future supervision models }\end{array}$ \\
\hline
\end{tabular}

Table 2. Guiding themes of the individual interviews

Task-based focus-groups

Inspired by the task-based focus-group design, two exercises were developed (Halkier, 2008). During the first exercise, the participants were asked to discuss strengths and weaknesses of individual and group supervision, respectively. In the second exercise, the participants were asked to identify conditions or specific factors they considered relevant for group supervision, and thus factors that should be taken into consideration when organising future courses based on group supervision. The interviewers adopted a facilitating position, i.e. they ex- 
plained the exercises and thereafter only interfered if something appeared unclear or the focus-group participants posed specific questions (Morgan, 1996).

\section{Data analyses}

All interviews were transcribed ad verbatim by one research assistant. The total transcribed data set covered a total of 155 pages (approximately 570 words per page). Of these, 93 pages covered the individual interviews, whereas the remaining 62 pages derived from the task-based focus-groups.

The data analysis consisted of a three-step procedure. The first step comprised an initial meaning condensation carried out by a research assistant without prior knowledge or prior hypotheses about strengths and weaknesses of individual and group supervision. This initial procedure was decided on in order to gain a valid initial meaning condensation across the data. In this way prior predispositions and preferences about individual and group supervision were not influencing the initial meaning condensation.

In the second step, another meaning condensation was carried out by PSS who had a prior knowledge of, and hypotheses about, the advantages and limitations of group and individual supervision. This step mainly consisted of a restructuring of the initial meaning condensation carried out in Step 1.

The third step consisted of a cluster analyses which aimed at digging deeper into the analyses and identifying clusters across the different themes identified in the second step of the analyses. The core of the cluster analysis consisted of qualitatively grouping answers into categories. This part of the analysis was carried out by both authors interchangeably and was directed towards the identification of clusters of narratives told within and across the main themes identified (Boje, 2008).

The supervision provided for the two Bachelor classes and the collection of the qualitative data for the present study were approved by the head of the study board at the Department where the study took place. No other approvals were required for the present study.

\section{Analyses and results}

Below the three steps of the analyses are described, i.e. the initial meaning condensation, the secondary meaning condensation and the actual cluster analysis are presented one at a time.

\section{Step 1: initial meaning condensation}

This first step of the analysis was carried out by a scholar without prior knowledge and hypotheses about group and individual supervision. The scholar was reading through the transcribed interviews searching for meaning categories. In this part of the analyses, the initial meaning condensation, a total of seven themes were identified: (1) social aspects, (2) 'more eyes', (3) frames, (4) the expert, (5) time, (6) difficult emotions, and (7) planning.

\section{Step 2: secondary meaning condensation}

In the second part of the meaning condensation the initial seven themes were validated against the second meaning condensation made by PSS, and the initial seven themes were restructured and combined into six thematic categories. These categories were considered to best fit the ordering and categorizing of the interviewees' perceptions and sense-making of their supervision experiences. The categories also related to the first aim of this study, i.e. the 
advantages and disadvantages of group and individual supervision. The categories and their definitional meaning codes were:

1. Social support: "not being alone", "being in the same boat", "being part of each other's process", "a feeling of comfort and ease", "creating new friendships", "team spirit", "companionship", and "helping others".

2. 'Sparring partners': "make use of each other's knowledge", "finding inspiration within the group", "several brains are better than one", "sparring in the group", "having a reference group", and "getting more eyes on your paper".

3. The expert: "students don't know enough about other students' subjects", "the supervisor's attitude and opinion weigh more than the group's attitudes and opinions", "students are not experts", "a feeling of not being competent enough to provide feedback", "individual supervision results in more progress than group supervision" and "individual supervision is better than group supervision when you are at a dead end".

4. Framing and structure of the supervision: "it is good to have a clear framework", "the importance of supervisor steering", "expectation agreement" and "clear feedback framework".

5. The time factor: "group supervision is time-consuming", "a lot of wasted time", "the sessions are too long", "you are getting tired", "less time-wasting in individual supervision", "the feedback to others is sometimes irrelevant or too specific to follow", "slow-moving and sluggish", and "individual supervision provides more individual focus".

6. Difficult emotions: "embarrassing", "withdrawal", "psychologically demanding", "intimidating", "performance anxiety", and "nervousness".

Step 3: cluster analyses

In the third and last step we re-visited the six thematic categories identified in the second step to identify between-theme patterns consisting of the main clusters provided us in data. This analytic step allows us to tease out main clusters related to the advantages and limitations of individual and group supervision, respectively. In this sense, the cluster analyses serve as our key results regarding the second aim of the article, i.e. specific situations under which individual and group supervision are appropriate.

\section{Social support}

According to the interviewees, engaging in group supervision produced a feeling of social support. Taking a share in each other's process as the dissertation develops was perceived as the 'social glue' making the group stick together. Group supervision promotes feelings of a team spirit, and being engaged in group supervision laid the foundation for new friendships and the basis for social relationships to evolve. This was considered most important in the beginning of the process because the social support was needed throughout the course of the Bachelor writing process. Group supervision was perceived as a social reference point, expressed by Anders as "being in the same boat" and being able to share and reflect upon each other's joy and frustration in writing a lengthy university dissertation, such as the Bachelor project. These plots 'glue together' the perceptions of social support of group supervision. This logic is succinctly articulated by Jens: 
So there [...] is the community aspect, I think it was very positive indeed. It felt like we were a team.

When we looked for the relation between group and individual supervision regarding social support an interesting inter-relation between the social support from the group and the individual perception of one's own process was discovered. Berit explains:

I could have a tendency to feel more insecure in the individual supervision if I had not seen how others [in my group] have done it; there's a kind of comfort in experiencing others being part of the same process as you and other being just as frustrated as you, and that others also encounter some resistance and stuff like that along the way, right?

Berit had no individual supervision as she participated in the class consisting of group supervision only. From her statement it appears that, based on her previous experiences with individual supervision, there is a tendency to feel more insecure in individual supervision. The fact that students may indeed feel less insecure about their individual processes when they take part in group supervision is a valuable insight into the specific social use and benefits of group supervision. This may be a reason for students to use group supervision strategically to receive social support and to be part of a group in what potentially could have been lonely process of writing a dissertation.

\section{2. 'Sparring partner'}

This theme relates to the use of the group as a place to spar with others. In group supervision the students got a feeling of writing their dissertations for other persons than only their supervisor and the external examiner. In fact, many students experienced that many new and relevant perspectives for their dissertations were brought up during the discussions in the group supervision. It was generally perceived as valuable to gain more perspectives and opinions on one's dissertation. Having more 'eyes' on the dissertation, in addition to the supervisor's eyes, was here mentioned as both helpful and important. As Diana put it:

Group supervision creates dynamics and dialogues and it contributes to the making of different understandings that emerge in the dialogues and by the fact that there are 'multiple brains', sitting and working on the same topic.

By "the same topic" Diana refers to the subject of one's own draft dissertation being the focus for feedback and discussion during the group supervision. Indeed, group supervisions create the opportunities to get 'sparring partners' and discussing one's paper and process with others, as it for example was expressed by Camilla:

Group supervision has the strength to provide you with a reference group in relation to where others are in their process, because it's a long process where you can get lost and lack the overview of how far you ought to be at a certain point in time.

Even though it was considered a strength to have a reference group, some interviewees also pointed to a negative aspect of a reference group throughout the process of writing an academic dissertation. This negative aspect was associated with the feeling of "not being far enough in the writing process" compared to others in the group. Despite feelings of "not being far enough", at least in comparison with the other group members, the students showed great responsibilities toward each other. 
As Anders called it, "it's the accountability" of group supervision, and,

you have responsibilities towards the others, even if you have not even progressed with your own paper. You still show up and take a share in the group supervision because that's what you have agreed to do. So, as a minimum you give the others [feedback]. Then you can only bite the bullet, because you are behind yourself.

\section{The expert}

This theme is related to the specific role and position of the supervisor. Even though peers were considered highly valuable in providing both social support and creating a reference group, all interviewees pointed to the supervisor as "the expert". All agreed that the supervisor held a superior position regarding the evaluation of the dissertation. The main theme of "the supervisor's opinion will always count for more" was very dominant. As Bolette puts it:

We could spend less time on peer feedback and instead get a bit more from the supervisor... it's the supervisor's words that matter to me, and not so much the words of the other students in the group. Because they didn't know what the supervisor wanted anyway.

The concept of "what the supervisor wants", i.e. what the supervisor expects, was a major concern for the interviewees, and it in some way seemed to generate an uncertainty when it came to providing good peer feedback. Generally, the interviewees said that it could be very difficult to provide good and competent feedback to their peers, in particular on subjects about which they did not have any prior knowledge. However, when the interviewees evaluated the feedback they received from their peers it was generally very positive. As Anders puts it:

I actually found the peer feedback that I received surprisingly good! Of course, it lacked the depth of the feedback my supervisor provided me because, of course, she has the overview. She is, I mean, she can see all the connections.

To sum up, feedback can be subdivided into two levels. One is the "necessary level" of feedback; i.e. the feedback and information that is needed in order for the student to feel reassured and confident in relation to the quality of his or her dissertation. The necessary feedback seems to be expected to be delivered from an expert supervisor. The other level is the "suggestion level"; i.e. the feedback and good suggestions that the student receives from her/his peers that you can be added if one believes it contributes to one's dissertation.

\section{Frame and structure of the supervision}

The dominant theme here was that the frame and structure of the supervision has to be clear and well-formulated. Most interviewees appreciated this, stating that "the more clearly defined the framework, the better it functions". All interviewees indicated that the frame and structure of the supervision setting was the most important factor, in order to secure a safe and pleasant environment for giving and receiving feedback. Bolette formulated this as follows:

The supervisor was so very structured that it somehow was like receiving individual supervision anyway. Because she made sure that we all got the same amount of time and that we went through each other's dissertations and provided feedback, so I think it's because of her structure that it succeeded as well as it did. 
All interviewees appreciated the rigid structure because they knew what to expect and what was expected of them. However, at the same time they all also wished for a more flexible structure: "you can do just as much planning as you can, but unexpected things can always occur along the way", Diana reasoned. Another informant, Camilla, focused on a different potentially problematic aspect of the frame and structure of the supervision:

Group supervision requires much communication and coordination before it succeeds between the group members. We experienced one group supervision where it kind of messed up with who was to provide peer feedback to whom. Two students provided peer feedback to one dissertation, and my partner and I were left out and received no peer feedback because no-one had read our dissertation, so it was anyway just our supervisor we received feedback from.

Thus, a clear frame and structure is central throughout the process, and it should be settled in the very beginning of the supervisory course. However, as the process and the product of each individual student matured over time, a need for individual supervision sessions seemed to develop.

\section{The time factor}

Group supervision was generally perceived as very time-consuming. With regard to the hours spent in group supervision, a main theme was identified as " $i$ 's too many hours you have to sit and concentrate, and in the end your brain just melts down". With regard to the time spend on preparation of feedback for the co-students a main plot was identified as "we are all already very busy with our own dissertations". Thus, the time factor was one theme that was highly related to group supervision, but in a negative way. The time factor was associated with a dominant discourse of "what is in it for me, compared to the time that I spend?" Most interviewees expressed frustrations of wasting time during the group session. As Alma puts it:

When you ask very specific questions [...] such questions that relates specifically to your own, and only to your own dissertation; then the rest of the group gets nothing out of it. We had one in my group who asked many, many, many specific questions, and it was almost...[like we fell asleep], we almost fell down from our chairs because it was so slow-moving to be part of.

As Alma further stated:

That's the drawback of group supervision; it has to be an open environment, and there are no stupid questions and you're allowed to ask what you want, then some very trivial and very specific questions are raised, that are not relevant for anyone else but yourself, so it's just... it's an act of balance and something you need to keep in mind.

Thus, it seems that some of the positive values of taking part in group supervision (e.g. social support and 'sparring partners') come at the price of time, and for the students it becomes a balance of giving and receiving.

\section{Difficult emotions}

This theme relates to the psychological distress and social discomfort associated with receiving feedback in front of others. One main plot of "putting strings to oneself in group supervision" was identified. During supervision, some interviewees experienced that they did 
not spend the whole one hour allocated to their project because they did not want to waste the time of their peers. As Dorthe explained it, "you are limiting yourself because you do not want to waste the time of others". This was further elaborated by Mie, "there is a bit of a competition going on. It related to the aspect that you don't want to be the one asking all the stupid questions. I mean, there is another kind of safe feeling when you are alone in supervision where there's no audience". Alma here touches upon the other main plot identified which is related to the narrative of "the safe feeling in individual supervision". This was particularly transparent among students that had felt behind with the progression of their dissertation compared to the other students. The underlying plot here was related to the difficult emotions of feeling vulnerable as a student, as someone who is still a novice learning and as a person taking part in social group supervision. Especially Anders provided us with insights into the dynamics of difficult emotions related to supervision, as he had particularly felt the group supervision to be personally challenging:

I didn't know there was so much stress related to [group supervision]. Or, stress and stress, but so... eh... because as an example, when we sat together, then I felt that I had to... eh... how shall I put it? ... perform in front of my supervisor and to perform toward others... So, it's a bit of a? performance... a bit nervousness.

The students may thus feel stressed or embarrassed when asking questions during group supervision or when having to show their work to others. These feelings were associated with a fear of being misunderstood or appear stupid in front of the group. In contrast, individual supervision was considered a setting where one can feel safe and cared for. Issues relating to social performance and personal self-efficacy seem relevant to the theme of difficult emotions in supervision; especially in relation to group supervision. As Anders expresses it:

Depending on your personality [how you feel in the group supervision]. For me it would be a bit embarrassing to get a moral pep talk or so from your supervisor in front of your peers because that would somehow be to lose face.

\section{Discussion}

The aim of the present study was firstly to identify potential advantages and disadvantages of individual and group supervision, and secondly to identify specific situations under which these two types of supervision are appropriate. On the basis of the qualitative analysis it is concluded that there are advantages and disadvantages to both types of supervision, and furthermore that the two types are appropriate under particular situations and circumstances. The advantages of individual supervision include more expert supervision from the supervisor, time allocated only to one's own dissertation, and then individual supervision is considered to be emotionally safe. In group supervision the advantages include social support from the peers, supervision and feedback from more than just the supervisor, inspiration from the peers, and feelings of having a reference group to which one can compare oneself. On the negative side, individual supervision lacks social support, peer inspiration and having a reference group. For group supervision the negative aspects include that it is time-consuming and that the students call for individual time with the supervisor.

When it comes to the role of the expert it appeared that all the students that were interviewed positioned the supervisor as 'the expert'. From our theoretical starting points of social interactionist theory and collaborative learning the aim of our supervision was that the students were to mutually interact with each other and learn from each other - not only from 
the supervisor. However, what the students noted was that the 'real expert' and 'the real supervision' was what they received from the 'real expert', i.e. the supervisor. This means that despite our attempt to co-define the supervision that should take place the students were primarily focused on the supervision they received from the supervisor. Despite an attempt to mutual engage all participants in the group and to provide with a coordinated setup where all students should engage in each other learning the students themselves primarily focused on the 'wise words of the supervisor'. In this regards our theoretical perspectives of collaborative learning and social interactionist fell short.

On the basis of the above analyses, we tentatively recommend that supervisors offer a mixed group/ individual course of supervision. Group supervision seem to be suitable in the beginning of the supervisory course, when the group dynamic is being established and when the supervision is more focused on the structure and process of the dissertation. Additionally, the students do not feel the same time pressure at the beginning of the supervisory course. Individual supervision, on the other hand, should be allocated during the end of the supervisory course, when specific content-related, expert supervision from the supervisor is needed. Individual supervision should conversely not be offered at the beginning of the supervisory course, as this will be an obstacle regarding the establishment of close ties between the members of the group.

To our knowledge, only two previous studies have examined combinations of individual and group supervision (Dysthe et al., 2006; Scholefield \& Cox, 2016). The authors of both of these studies recommend the use of mixed supervision models. However, unlike the present study, these earlier studies did not investigate the reasons for, and situations under which, either of the two types of supervision should be recommended. Generally, students are provided with social and supportive benefits in group supervision. They are able to share and exchange ideas and knowledge, and they become parts of a social group. Individual supervision, on the other hand, provides a personal space. During individual supervision, students feel emotionally and personally safe in asking questions and expressing feelings and thoughts without a peer audience. Group supervision is recommended in the beginning of a supervision course when structure, dialogue, inspiration and social grouping are among the central needs of the students. Towards the end of the supervision course, closer to the deadline for submitting their dissertations, students become focused on their own dissertation and less so on those of their peers. As in the study conducted by Dysthe et al. (2006), individual supervision creates the opportunity to ask very specific questions and ask for specific advice. This finding is supported and elaborated upon in the present study. However, the way that the individual sessions should be implemented may vary - from pre-planned 1-hour sessions to a 10-minute meeting where a certain matter appearing in the group supervision can be clarified and settled between one student and the supervisor. In conclusion, based upon the present study and the previous empirical literature, we recommend a mixed supervision model consisting of mostly group supervision adopted early in the process switching to individual supervision toward the end of the process.

Regarding the Study Progress Reform we believe that some of the advantages of group supervision may indeed be aligned with the thoughts and aims of this reform. First and foremost the importance of social support stands out as a central factor. The students themselves describe this as they are 'glued together' and that they have a feeling of group spirit. This gluing together and group spirit seem central in order for them to keep up with deadlines and eventually handing in the dissertation on time. These social and supportive 
benefits were also pointed at as advantaged of the two previous studies comparing individual and group supervision (Dysthe et al., 2006a; Scholefield \& Cox, 2016). This can be explained by interactionism under which what becomes particular important is that the students start sharing a relationship with each other within the group. This to a much larger degree that they would have done if they had not been forced to take part in a supervisory group. When they are assigned to the group they start interacting within the group, and they begin to share relations and situations with one another.

\section{Strengths and limitations of the present study}

One obvious strength of the present study is that it is, to our knowledge, the first study to investigate the specific advantages and limitations of group and individual supervision, and to look into the specific circumstances under which these are appropriate. Another strength was the adaptation of a comparative design investigating two different supervisory courses taking place over the same period of time and with similar structures for the two classes.

On the other hand, it is considered a limitation that thestudy was based on a relatively small number of individual interviews and focus-groups. However, the extent and number of interviewees resembles most other studies in the field. On the positive side we adapted a qualitative mixed-methods approach, including both individual interviews and task-based focusgroup interviews. This approach ensured responses to different types of dialogues and questions, possibly generating a broader spectrum of responses. Along the same lines it may also be a disadvantage that we simply exchanged and interviewed each other's students, instead of having external experts conducting the actual interviews.

The circumstances under which the study was conducted, is also considered a limitation. We had to adapt the study design to the already existing and non-flexible teaching frame. For example, the two supervisors different didactical and personal teaching and supervision styles could potentially have influenced the results. Also, most students wrote their dissertations individually, whereas some wrote the dissertations in smaller groups of up to three students. Although we a priori attempted to align as many factors as possible these factors would not be aligned and could potentially have influenced the results.

A final potential limitation of the present study could be our own predispositions to and attitudes towards individual and group supervision, respectively. Such attitudes could potentially have a large impact of the acquired results. However, we have attempted to accommodate such attitudes in a number of ways. First and foremost, we have had a research assistant without prior knowledge about and attitudes toward individual and group supervision to carry out the initial meaning condensation. Secondly, the two authors probably had different preferences towards supervision prior to the launching of the project. We consider such different attitudes a strength that have had a positive and enlightened influenced the project.

\section{Perspectives}

The present study could advantageously be replicated in other organisational settings and with other types of students, including students from other departments and faculties and at other academic levels. Further, in the present study, no attention was, for example, paid to the specific role or type of the supervisor. Some have argued that supervisors can take on specific roles including a caring 'mother'-type (a caring supervisor), a process-oriented 'consultant' (a process-focused supervisor) and a content-related 'academic'-type (an 
archetypical professor supervisor) (Holmberg, 2006). In the present study, the two supervisors may have different supervisory styles that could have affected the course of the supervision and hence the results. On this basis it is recommended that future research investigate what specific roles the supervisors may take and whether such different roles are preferred by the students under particular circumstances and during different parts of the supervisory process.

In the present study no attention was paid to the dynamics within the individual groups. However, we observed that some groups had better group dynamics than others. As supervisors, we recommended the students to make use of their group, i.e. make use of the group in study colloquia taking place between the individual supervision sessions, or indeed to communicate in a Facebook group. On this basis it is recommended that future research investigate the specific roles of student colloquia or simply just student communication within the group in relation to supervision. The group does seem to play a pivotal role for the students, but we are yet to know the specific grounds on which these should be formed and how the student colloquia should be verbalised - should they, for example, be formalised and compulsory?

A final aspect that needs more attention in future studies is the specific role of individual feedback forms. How should feedback be given, specifically to student in groups in order to optimise the frames under which feedback is given to the students? These may be relevant aspects for future research to investigate further.

\section{References}

Akister, J., Williams, I., \& Maynard, A. (2009). Using group supervision for undergraduate dissertations: a preliminary enquiry into the student experience. Practice and Evidence of the Scholarship of Teaching and Learning in Higher Education.

Baker, M. (2014). Supervising undergraduate research: A collective approach utilising groupwork and peer support.

Blumer, H. (1937). Social disorganization and individual disorganization. American Journal of Sociology, 42(6), 871-877.

Boje, D. M. (2008). Storytelling organizations. Sage.

Christie, H., Tett, L., Cree, V. E., Hounsell, J., \& McCune, V. (2008). 'A real rollercoaster of confidence and emotions': learning to be a university student. Studies in Higher Education, 33(5), 567-581. https://doi.org/10.1080/03075070802373040

Dillenbourg, P. (1999). What do you mean by collaborative learning. Collaborative-Learning: Cognitive and Computational Approaches, 1, 1-15.

Dysthe, O., Samara, A., \& Westrheim, K. (2006a). Multivoiced supervision of Master's students: a case study of alternative supervision practices in higher education. Studies in Higher Education, 31(3), 299-318.

Dysthe, O., Samara, A., \& Westrheim, K. (2006b). Multivoiced supervision of Master's students: a case study of alternative supervision practices in higher education. Studies in Higher Education, 31(3), 299-318. https://doi.org/10.1080/03075070600680562 
Ginn, F. (2014). "Being like a researcher": supervising Masters dissertations in a neoliberalizing university. Journal of Geography in Higher Education, 38(1), 106-118. https://doi.org/10.1080/03098265.2013.836746

Goffman, E. (2005). Interaction ritual: Essays in face to face behavior. AldineTransaction.

Halkier, B. (2008). Fokusgrupper, 2. udg. Frederiksberg: Forlaget Samfundslitteratur.

Holmberg, L. (2006). Forskare, consult eller morsa: handledares uppfattning om kvalité vid handledning av examensuppsatser. Retrieved from http://www.divaportal.org/smash/record.jsf?pid=diva2\%3A479732\&dswid=-6101

Jensen, H. N. (2015). Opgave- og skrivevejledning i klynger. Samfundslitteratur.

Kangasniemi, M., Ahonen, S.-M., Liikanen, E., \& Utriainen, K. (2011). Health science students' conceptions of group supervision. Nurse Education Today, 31(2), 179-183. https://doi.org/10.1016/j.nedt.2010.05.015

Kvale, S., \& Brinkmann, S. (2009). Interviews: Learning the craft of qualitative interviewing. London: Sage.

Lillejord, S., \& Dysthe, O. (2008). Productive learning practice - a theoretical discussion based on two cases. Journal of Education and Work, 21(1), 75-89. https://doi.org/10.1080/13639080801957154

Litosseliti, L. (2003). Using focus groups in research. A\&C Black.

Ministry of Education and Research. (2015). Fremdriftsreformen. Retrieved 16 April 2017, from http://ufm.dk/uddannelse-og-institutioner/indsatsomrader/fremdriftsreformen

Morgan, D. L. (1996). Focus groups as qualitative research (Vol. 16). Sage publications.

Nordentoft, H., Thomsen, R., \& Wichmann-Hansen, G. (2013). Collective academic supervision: a model for participation and learning in higher education. Higher Education, 65, 581-593.

Ray, D., \& Altekruse, M. (2000). Effectiveness of group supervision versus combined group and individual supervision. Counselor Education and Supervision; Washington, 40(1), 19.

Robotham, D., \& Julian, C. (2006). Stress and the higher education student: a critical review of the literature. Journal of Further and Higher Education, 30(2), 107-117. https://doi.org/10.1080/03098770600617513

Samara, A. (2006). Group supervision in graduate education: a process of supervision skill development and text improvement. Higher Education Research \& Development, 25(2), 115-129. https://doi.org/10.1080/07294360600610362

Scholefield, D., \& Cox, G. (2016). Evaluation of a model of dissertation supervision for 3rd year B.Sc. undergraduate nursing students. Nurse Education in Practice, 17, 78-85. https://doi.org/10.1016/j.nepr.2015.11.006 
Stallman, H. M. (2010). Psychological distress in university students: A comparison with general population data. Australian Psychologist, 45(4), 249-257. https://doi.org/10.1080/00050067.2010.482109

Van Biljon, J., Van Dyk, T., \& Naidoo, L. (n.d.). Towards Increasing Supervision Capacity: The Pyramid Cohort Supervision Model. SACLA, 2014(6), 166-173.

Yamada, K. (2013). Group supervision and Japanese students' successful completion of undergraduate theses. Education Research and Perspectives (Online); Crawley, 40, 3057. 